\title{
Comparison of hysterosalpingography and laparoscopy in evaluation of female infertility
}

Authors:

Farideh Gharekhanloo ${ }^{1}$

Fereshteh Rastegar ${ }^{2}$

\section{Affiliations:}

Hamadan University of Medical

Sciences, Hamadan, Iran

\section{Corresponding author:}

Farideh Gharekhanloo

E-mail:

dr_gharekhanloof@yahoo.com

Keywords: Laparoscopy, Infertility, Hysterosalpingography, Diagnostic accuracy

\begin{abstract}
Background and Objectives: Laparoscopic surgery (LS) is the most important diagnostic technique for the detection of causes of infertility; however, this method is accompanied by some setbacks. Given the noninvasive nature and cost-effectiveness of hysterosalpingography (HSG), it is widely used as the first-line approach for the evaluation of the patency of the fallopian tubes and uterine anomalies in female infertility. Herein, we aimed to compare the diagnostic values of HSG with LS in the assessment of patency of the fallopian tubes and peritoneal disease in infertile women.
\end{abstract}

Materials and Methods: This prospective, cross-sectional study was performed on 115 infertile women admitted to the Department of Obstetrics and Gynecology in Fatemiyeh Teaching Hospital, Hamedan, Iran, during March 2011September 2012. Tubal patency, peritubal adhesion, uterine anomalies, and tubo-ovarian abscess (TOA) findings in HSG were compared with laparoscopic findings. Data was analyzed using McNemar's test and Cohen's Kappa.

Results: The sensitivity, specificity, and accuracy of HSG for the detection of unilateral and bilateral tubal occlusion were $75 \%, 91.2 \%, 89.5 \%, 75 \%, 97.2 \%$, and $96.6 \%$, respectively. Furthermore, false-positive and false-negative rates of HSG for the detection of unilateral and bilateral tubal occlusion were $8.7 \%$ and $25 \%$, respectively. The accuracy of HSG in detecting uterine anomalies and hydrosalpinx were $93.3 \%$ and $93.9 \%$, respectively. Peritubal adhesion and TOA were detected in $61 \%$ of the cases with normal HSG. In addition, of the nine cases of bilateral tubal occlusion detected by HSG, six cases were confirmed to have bilateral occlusion using laparoscopy. The comparison between HSG and LS techniques showed a significant difference in diagnosis of distal fallopian tube occlusion $(\mathrm{P}=0.021)$ and unilateral fallopian tube occlusion $(\mathrm{P}<0.001)$ among infertile women. The comparison between HSG and LS techniques demonstrated a significant difference in diagnosis of TOA $(\mathrm{P}<0.001)$ and peritubal adhesion $(\mathrm{P}=0.033)$.

Conclusion: It seems that the findings of HSG regarding occlusion, hydrosalpinx, and uterine anomalies are reliable. However, due to its low sensitivity in detecting peritubal adhesion, performing LS before initiation of treatment in these patients is necessary to rule out adhesion and to confirm tubal patency. 


\section{Introduction}

Inability to conceive despite having regular unprotected intercourse during one year or the inability to carry a pregnancy to full term is considered as infertility (1). In general, the prevalence of infertility is estimated to be $10-15 \%$ among young couples (2). Ovulatory problems are the most common cause of female infertility. In $80 \%$ of the cases, infertility usually occurs due to some conditions such as endometriosis or polycystic ovary syndrome (PCOS), while in $20 \%$ of the cases the etiology of this condition is unexplained (3). According to a report in 1997, about 3-7\% of all couples have an unresolved problem of infertility. However, experiencing infertility for at least one year is reported in $12-28 \%$ of cases (4).

Due to the infertility problems and long duration of response to treatment, its correct diagnosis to provide appropriate treatment strategies is highly critical. There are several methods for the treatment of female infertility. Furthermore, identifying the etiology of infertility and its subsequent treatment does not always lead to viable pregnancy and live birth (3).

Considering the high rate of infertility in young couples, its early and correct diagnosis is of great importance. Hysterosalpingography (HSG) and laparoscopic surgery (LS) are the two most important diagnostic procedures for the detection of causes of infertility (5). Given the noninvasive nature and cost-effectiveness of HSG, it is widely used as the first-line approach for the assessment of the patency of the fallopian tubes and uterine anomalies in the routine fertility workup. As compared to HSG, LS is a less invasive surgical approach, which is performed through making small incisions. In this surgical technique, the surgeon can see into patient's body through the image obtained from a video camera (6).

Although laparoscopy is a good predictor of treatment-independent pregnancy, this method is accompanied with difficulties that require special training. On the other hand, this technique is more expensive and unsafe than other diagnostic methods (7). For these reasons, the use of other diagnostic techniques is recommended by physicians. The aim of this study was to evaluate and compare the diagnostic values of HSG with LS in the assessment of patency of the fallopian tube and peritoneal disease in infertile women.

\section{Materials and Methods}

This prospective, cross-sectional study was performed on women aged 18-42 years, who were admitted to Department of Obstetrics and Gynecology in Fatemiyeh Teaching Hospital, Hamedan, Iran, during March 2011-September 2012 (18 months).

The sample size was estimated at 115; the participants were chosen through convenience sampling. The inclusion criteria were infertility diagnosis based on World Health Organization (WHO) criteria, abnormal HSG, having laparoscopy indications, and normal HSG without response to three treatment courses for infertility. The exclusion criteria comprised of age less than 18 years and more than 42 years, history of severe sperm pathology, undergoing in-vitro fertilization (IVF), contraindication for LS, and over 12 months elapsed from the last HSG.

The plan was approved by the Ethics Committee of Hamedan University of Medical Sciences. Before the outset of the study, the participants were assured of the confidentiality of the data, and informed consent was obtained from all the participants. 
First, the personal data including gender, parity, gravidity, infertility length, type of infertility (primary or secondary), and history of pelvic and abdominal surgery were gathered, and then the results of HSG and LS were recorded based on radiologist report.

In the next step, the patients were divided in two groups of HSG and LS. The two techniques were performed by an infertilitist and their findings were provided in a report sheet designed for the study. Regarding laparoscopy as the reference standard, tubal patency, peritubal adhesion, uterine anomalies, and tubo-ovarian abscess (TOA) findings in HSG were compared with laparoscopic findings. In this study, HSG and LS were compared by McNemar's test. Cohen's Kappa coefficient was applied to evaluate inter-rater agreement for categorical variables. Data was analyzed using SPSS, version 21 .

\section{Results}

Mean age of the patients was $29.3 \pm 62.5$ years (age range: 18-42 years). The mean gravidity was $0.66 \pm 0.99$ (range: $1-5$ ). The mean of parity was $0 \pm 0.69$ (range: $0-3)$. The mean of infertility length was $4.83 \pm 3.47$ years (range: 1-20 years). The remaining information is presented in Table 1 and the frequency of various detections by LS and HSG is shown in Table 2.

According to Table 2, the highest frequency was noted for unilateral proximal tubal occlusion in HSG method and TOA had the highest frequency in LS method, while the lowest frequencies belonged to unilateral and bilateral distal tubal occlusion.

The obtained data through HSG and LS is compared in Table 3. Based on McNemar's test, the comparison between HSG and LS showed no significant differences in diagnosis of unilateral proximal tubal occlusion $(\mathrm{P}=0.28)$, bilateral proximal tubal occlusion $(\mathrm{P}=0.28)$, proximal fallopian tube occlusion $(\mathrm{P}=0.076)$, unilateral proximal tubal occlusion $(\mathrm{P}=0.12)$, unilateral distal tubal occlusion $(\mathrm{P}=1)$, and bilateral fallopian tubal blockage $(\mathrm{P}=0.208)$ among infertile women.

Cohen's kappa coefficient, which evaluates the diagnostic agreement between HSG and LS, was calculated at 0.32 for unilateral proximal tubal occlusion and 0.317 for unilateral distal tubal occlusion. It indicated a relative agreement between findings of these two techniques. Cohen's kappa coefficient was calculated at 0.301 for bilateral proximal tubal occlusion, showing a low congruity between these two techniques. Furthermore, Cohen's kappa coefficient was estimated to be 0.301 for bilateral distal tubal occlusion, 0.278 for proximal fallopian tube occlusion, and 0.269 for bilateral fallopian tubal blockage $(\mathrm{P}=0.208)$, demonstrating a low consistency between these two techniques.

The comparison between HSG and LS techniques showed a significant difference in diagnosis of distal fallopian tube occlusion $(\mathrm{P}=0.021)$ and unilateral fallopian tube occlusion $(\mathrm{P}>0.001)$ among infertile women. Cohen's kappa coefficient showed a low agreement between these two techniques in diagnosis of distal tubal occlusion $(\mathrm{K}=0.27)$ and unilateral fallopian tube occlusion $(\mathrm{K}=0.16)$.

In addition, there was no significant difference in diagnosis of congenital uterine anomalies $(\mathrm{P}=0.125)$ and hydrosalpinges $(\mathrm{P}=0.26)$ between HSG and LS methods. Cohen's kappa coefficient showed a relative consistency in diagnosis of congenital uterine anomalies $(\mathrm{K}=0.558)$ and a low coordination in diagnosis hydrosalpinges $(\mathrm{K}=0.18)$ between these two techniques.

The comparison between HSG and LS techniques demonstrated a significant difference in diagnosis of TOA $(\mathrm{P}>0.001)$ 
and peritubal adhesion $(\mathrm{P}=0.033)$. Cohen's kappa coefficient indicated a low agreement between these two techniques in diagnosis of tubo-ovarian abscess $(\mathrm{K}=0.155)$ and peritubal adhesion $(\mathrm{K}=0.111)$. In addition, there was no significant difference in diagnosis of normal fallopian tubes $(\mathrm{P}=0.39)$ and pathologic findings $(\mathrm{P}=0.23)$ between HSG and LS. Cohen's kappa coefficient demonstrated a low coordination in diagnosis of normal fallopian tubes $(\mathrm{K}=0.115)$ and pathologic findings $(\mathrm{K}=0.22)$ between these two techniques.

The detection difference of HSG and LS is presented in Table 4. According to our findings, out of the 113 patients with normal HSG, 58 were normal and 18 diagnosed with TOA. Of the patients in whom the HSG was normal, 17 patients had peritubal adhesion, nine had hydrosalpinges, two congenital uterine anomalies, six bilateral proximal tubal occlusion, three unilateral proximal tubal occlusion, two bilateral distal tubal occlusion, and one distal tubal occlusion. The rates of false positive and false negative results, as well as positive predictive value, negative predictive value, sensitivity, specificity, and accuracy of different uterine abnormalities in HSG are presented in Table 5.

\section{Discussion}

According to our findings, unilateral proximal tubal occlusion was a common detection in HSG, while TOA was more frequent in LS technique. Unilateral and bilateral distal tubal occlusions were of low frequency. There was a relative agreement in diagnosis of unilateral proximal tubal occlusion and unilateral distal tubal occlusion between these two techniques. Additionally, a low congruity was observed in the diagnosis of bilateral proximal tubal occlusion, bilateral distal tubal occlusion, proximal fallopian tube occlusion, unilateral and bilateral fallopian tubal blockage, hydrosalpinges, TOA, and normal fallopian tubes between HDG and LS techniques. Additionally, there was a relative coordination in diagnosis of congenital uterine anomalies between two these techniques.

Although LS is superior to HSG in detection of peritubal adhesions and other pelvic pathologies, use of LS is limited due to complications, costs, and stress imposed to patients. HSG should be used as a primary technique for the diagnosis of intrauterine pathologies; however, the use of this technique is not adequate for the diagnosis of all intrauterine pathologies (8).

One study by Mol et al. showed that LS is a better predictor of treatmentindependent pregnancy compared to HSG. Based on the mentioned study, treatmentindependent pregnancy was decreased with reducing bilateral occlusion of the fallopian tube. Although Mol et al. showed that LS is better than HSG in the diagnosis of intraabdominal injuries, HSG had a better performance in detection of intrauterine pathologies (9). In our study, the sensitivity of HSG was lower and its specificity in pathologic findings was higher than those obtained by Mol et al. This discrepancy might be due to differences in the applied instruments or other confounding factors.

Similar to our study, accuracy of HSG and LS was compared in a study by Tvarijonaviciene et al., which showed the diagnostic value of HSG was low in general tubal pathology and peritubal adhesion detection and high in tubal occlusion. According to Tvarijonaviciene et al., the sensitivity and specificity of HSG in detection of bilateral occlusion were $89.5 \%$ and $90 \%$, respectively, which was in agreement with our findings. In our study, specificity and sensitivity of HSG regarding peritubal adhesion were higher and lower, respectively, in comparison with the results of Tvarijonaviciene (10). 
According to a study by Lavy et al., the negative predictive value of HSG is high in the presence of normal findings; however, the possibility of false detection of tubal patency is low if tube occlusion is indicated by HSG. The risk of false detection of tube occlusion is moderate, which may be due to secretion of contrast agent into the tube; therefore, LS should be recommended in all the patients suspected of bilateral tubal occlusion by HSG (11).

The specificity of HSG in the diagnosis of proximal occlusion was estimated at $70 \%$ in a study by Shah et al. (12), which was higher compared to our finding. The positive predictive value of HSG in diagnosis of bilateral proximal occlusion was lower in our study. Therefore, HSG is an accurate technique for the diagnosis of patency of the fallopian tube, but bilateral occlusion is diagnosed with low sensitivity. This may be as a result of severe stress, pain, and spasms during gadolinium enhancement, which leads to false proximal occlusion detection. More than one-third of our patients had history of at least one miscarriage or curettage, which causes cervical patency and secretion of contrast agent. Consequently, it might cause invisibility of spillage leading to false proximal occlusion detection.

According to another study by Bosteels et al., percent error by HSG in detection of bilateral occlusion of the fallopian tube was $42 \%$, therefore, the use of LS is necessary if bilateral occlusion of the fallopian tube is detected by HSG. Also, the sensitivity and specificity of HSG were $65 \%$ and $83 \%$, respectively (13), which was in accordance with our results.

Waheed et al. showed a significant difference between HSG and LS techniques in diagnostic accuracy of patency of the fallopian tubes; however, there was no difference in diagnostic accuracy of hydrosalpinges between these two techniques (14), which was confirmed by our results.

The superiority of LS in detection of ovarian, peritubal, and intra-abdominal pathologies was demonstrated by Sakar et al. Their study showed that the sensitivity and specificity of HSG in diagnosis of peritubal adhesion were $63 \%$ and $89 \%$, respectively (8). Moreover, low sensitivity and high specificity in diagnosis of TOA was indicated by HSG, which was confirmed by our study.

Perquin et al. showed HSG has a relative sensitivity and high specificity in detection of tubal obstruction, while its sensitivity for peritubal adhesion and adnexal masses was low (15). Similar to our study, Sakar et al. showed LS is a better technique for detection of peritoneal lesions.

In a study by Goynumer et al., the sensitivity of HSG regarding pathologic findings was estimated at $80 \%$, which was somewhat consistent with the results of our study. However, the rate of HSG specificity was calculated higher than $80 \%$ in our study, while it was $75 \%$ in the Goynumer study. That study showed HSG is not appropriate for definitive diagnosis of tubal obstruction, endometriosis pathologies, peritubal pathologies, and other peritoneal lesions (16).

The accuracy of HSG regarding pathologic findings was confirmed in $75.1 \%$ of patients in a study by Mohammadbeigi et al. (17), which was calculated at $73.4 \%$ in our study. According to one study by Sakar et al., $45 \%$ of patients showed normal findings using $\mathrm{HSG}$, while $65 \%$ of them had pathological findings by LS (8). In our study, the rate of false-positive results was estimated at $42 \%$, the majority of which were TOA and peritubal adhesion.

Based on our study, the diagnostic accuracy of both HSG and LS is relatively 
equal for detection of hydrosalpinges and intrauterine abnormalities. Since the HSG is less invasive and expensive in comparison with LS, it can be introduced as a better technique for diagnosis of these problems.

Generally, HSG had a median sensitivity and high specificity in diagnosis of fallopian tube occlusion, which is known as a major cause of female infertility (18). LS is a costly and invasive procedure, with high risk of organ perforation and vascular injuries. Nevertheless, it is an efficient and sensitive technique for identifying some causes of infertility such as endometriosis and pelvic adhesions (14), which are not detectable by other diagnostic techniques, as was observed in our study.

Although HSG is a safe, cost-effective, and less invasive technique for the diagnosis of endometrial and tubal pathology, LS is a more appropriate and reliable technique in the diagnosis of endometriosis, pelvic adhesions, and other intrauterine pathologies. Therefore, these two techniques cannot be used interchangeably, but can be used as complements.

\section{Conclusion}

Our study revealed that HSG is a reliable technique for the detection of tubal occlusion, hydrosalpinges, and uterine anomalies. However, given low sensitivity in detecting peritubal adhesion, performing LS before initiation of treatment in these patients is recommended to rule out adhesion and confirm tubal patency. 
Medical Research Archives, Vol. 5, Issue 6, June 2017

Comparison of hysterosalpingography and laparoscopy in evaluation of female infertility

\section{References}

1. Reviews C. Anatomy and Physiology for Midwives: Medicine, Internal medicine: Cram101; 2016.

2. Baumann L. Cosmetic Dermatology: Principles and Practice, Second Edition: Principles \& Practice: McGraw-Hill Education; 2008.

3. Ried K, Stuart K. Efficacy of Traditional Chinese Herbal Medicine in the management of female infertility: a systematic review. Complementary therapies in medicine. 2011;19(6):319-31.

4. Himmel W, Ittner E, Kochen MM, Michelmann HW, Hinney B, Reuter M, et al. Management of involuntary childlessness. $\mathrm{Br} \mathrm{J}$ Gen Pract. 1997;47(415):111-8.

5. Saunders RD, Shwayder JM, Nakajima ST. Current methods of tubal patency assessment. Fertility and sterility. 2011;95(7):2171-9.

6. Pasic RP, Brill AI, Levine R. A Practical Manual of Laparoscopy and Minimally Invasive Gynecology: A Clinical Cookbook: CRC Press; 2007.

7. Tayebeh N, Fatemeh K, Abbas B. Comparison of chlamydia infection prevalence between patients with and without ectopic pregnancy using the PCR method. Ginekol Pol. 2012;83:819-21.

8. Sakar MN, Gul T, Atay AE, Celik Y. Comparison of hysterosalpingography and laparoscopy in the evaluation of infertile women. Saudi medical journal. 2008;29(9):1315-8.

9. Mol BW, Collins JA, Burrows EA, Van der Veen F, Bossuyt PM. Comparison of hysterosalpingography and laparoscopy in predicting fertility outcome. Human Reproduction. 1999;14(5):1237-42.

10. Tvarijonavičienė E, Nadišauskienė RJ. The value of hysterosalpingography in the diagnosis of tubal pathology among infertile patients. Medicina (Kaunas). 2008;44(6):439-48.
11. Lavy Y, Lev-Sagie A, Holtzer H, Revel A, Hurwitz A. Should laparoscopy be a mandatory component of the infertility evaluation in infertile women with normal hysterosalpingogram or suspected unilateral distal tubal pathology? European Journal of Obstetrics \& Gynecology and Reproductive Biology. 2004;114(1):64-8.

12. Shah S, Towobola O, Masihleho $M$. Diagnosis of fallopian tube patency. East African medical journal. 2005;82(9).

13. Bosteels J, Van Herendael B, Weyers S, D'hooghe $T$. The position of diagnostic laparoscopy in current fertility practice. Human reproduction update. 2007;13(5):477-85.

14. Waheed S, Mazhar R, Khan N, Rafi M. The Comparison of Hysterosalpingography and Laparoscopy in Predicting Fertility. Annals of King Edward Medical University. 2007;13(3):202.

15. Perquin D, Dörr $\mathrm{P}$, De Craen A, Helmerhorst F. Routine use of hysterosalpingography prior to laparoscopy in the fertility workup: a multicentre randomized controlled trial. Human Reproduction. 2006;21(5):1227-31.

16. Goynumer G, Yetim G, Gokcen O, Karaaslan I, Wetherilt L, Durukan B. Hysterosalpingography, Laparoscopy or both in the Diagnosis of Tubal Disease in Infertility. 2008.

17. Seyedoshohadaei F, Mohammadbeigi R, Tahmuri A, Ghaderi E. Frequency and related factors of tubal patency after methotrexate treatment in women with ectopic pregnancy. Journal of Obstetrics and Gynaecology Research. 2016;42(3):286-90.

18. Broeze K, Opmeer B, Van Geloven N, Coppus S, Collins J, Den Hartog J, et al. Are patient characteristics associated with the accuracy of hysterosalpingography in diagnosing tubal pathology? An individual patient data metaanalysis. Human reproduction update. 2010:dmq056. 
Medical Research Archives, Vol. 5, Issue 6, June 2017

Comparison of hysterosalpingography and laparoscopy in evaluation of female infertility

\section{Tables}

Table 1. Personal information of the participants

\begin{tabular}{|c|c|c|c|c|c|}
\hline \multicolumn{2}{|c|}{ General information } & \multirow{2}{*}{\begin{tabular}{|l|} 
Percent \\
32.5 \\
\end{tabular}} & \multicolumn{2}{|l|}{ General information } & \multirow{2}{*}{$\begin{array}{l}\text { Percent } \\
59.1\end{array}$} \\
\hline Age & $<25$ & & \multirow[t]{6}{*}{ Gravidity } & $\begin{array}{l}\text { No. } \\
\text { fertility }\end{array}$ & \\
\hline & $25-30$ & 30.7 & & 1 & 25.2 \\
\hline & $30-35$ & 18.4 & & 2 & 8.7 \\
\hline & $35-40$ & 15.8 & & 3 & 5.2 \\
\hline & \multirow[t]{2}{*}{$>40$} & \multirow[t]{2}{*}{2.6} & & 4 & 0.9 \\
\hline & & & & 5 & 0.9 \\
\hline \multirow[t]{4}{*}{ Parity } & No & 64.3 & \multirow{4}{*}{$\begin{array}{l}\text { Infertility length } \\
\text { (years) }\end{array}$} & $1-5$ & 73.7 \\
\hline & 1 & 27.8 & & $5-10$ & 19.3 \\
\hline & 2 & 6.1 & & $10-15$ & 5.3 \\
\hline & 3 & 1.7 & & $15-20$ & 1.7 \\
\hline \multirow{2}{*}{$\begin{array}{l}\text { Type of } \\
\text { infertility }\end{array}$} & Primary & 58.3 & \multirow{2}{*}{$\begin{array}{l}\text { History of pelvic and } \\
\text { abdominal surgery }\end{array}$} & Yes & 30.4 \\
\hline & Secondary & 41.7 & & No & 69.6 \\
\hline
\end{tabular}


Medical Research Archives, Vol. 5, Issue 6, June 2017

Comparison of hysterosalpingography and laparoscopy in evaluation of female infertility

Table 2. The frequency of detection data by laparoscopic surgery and hysterosalpingography

\begin{tabular}{|l|l|l|}
\hline Techniques & Findings & Percent \\
\hline Hysterosalpingography & Normal & 52.2 \\
\cline { 2 - 3 } & Unilateral proximal tubal occlusion & 29.9 \\
\cline { 2 - 3 } & Unilateral distal tubal occlusion & 11.3 \\
\cline { 2 - 3 } & Peritubal adhesion & 6.6 \\
\cline { 2 - 3 } & Congenital uterine anomalies & 5.2 \\
\cline { 2 - 3 } & Hydrosalpinges & 1.7 \\
\cline { 2 - 3 } & Bilateral proximal tubal occlusion & 1.7 \\
\cline { 2 - 3 } & Bilateral distal tubal occlusion & 1.7 \\
\cline { 2 - 3 } & Tubo-ovarian abscess (TOA) & 1.7 \\
\hline Laparoscopic surgery & Normal & 46.1 \\
\cline { 2 - 3 } & TOA & 17.4 \\
\hline & Peritubal adhesion & 17.4 \\
\cline { 2 - 3 } & Hydrosalpinges & 9.6 \\
\hline & Congenital uterine anomalies & 9.6 \\
\cline { 2 - 3 } & Unilateral proximal tubal occlusion & 8.7 \\
\cline { 2 - 3 } & Bilateral proximal tubal occlusion & 7 \\
\hline \multirow{5}{*}{} & Unilateral distal tubal occlusion & 3.5 \\
\hline & Bilateral distal tubal occlusion & 3.5 \\
\hline
\end{tabular}


Medical Research Archives, Vol. 5, Issue 6, June 2017

Comparison of hysterosalpingography and laparoscopy in evaluation of female infertility

Table 3. The comparison of hysterosalpangiography and laparoscopic

\begin{tabular}{|c|c|c|c|c|c|c|c|c|c|}
\hline \multirow{2}{*}{\multicolumn{2}{|c|}{$\begin{array}{l}\text { Hysterosalpingo- } \\
\text { graphy }\end{array}$}} & \multicolumn{2}{|c|}{$\begin{array}{l}\text { Laparosco- } \\
\text { pic surgery }\end{array}$} & \multirow[t]{2}{*}{ Total } & \multirow{2}{*}{\multicolumn{2}{|c|}{ Hysterosalpingography }} & \multicolumn{2}{|c|}{$\begin{array}{l}\text { Laparoscopic } \\
\text { surgery }\end{array}$} & \multirow[t]{2}{*}{ Total } \\
\hline & & Yes & No & & & & Yes & No & \\
\hline \multirow{3}{*}{$\begin{array}{l}\text { Unilateral } \\
\text { proximal } \\
\text { tubal } \\
\text { occlusion }\end{array}$} & Yes & 7 & 17 & 24 & \multirow{3}{*}{$\begin{array}{l}\text { Bilateral } \\
\text { fallopian } \\
\text { tubal } \\
\text { occlusion }\end{array}$} & Yes & 6 & 3 & 9 \\
\hline & No & 3 & 88 & 91 & & No & 2 & 104 & 106 \\
\hline & Total & 10 & 105 & 115 & & Total & 8 & 107 & 115 \\
\hline \multirow{3}{*}{$\begin{array}{l}\text { Unilateral } \\
\text { distal tubal } \\
\text { occlusion }\end{array}$} & Yes & 3 & 10 & 13 & \multirow{3}{*}{$\begin{array}{l}\text { Congenital } \\
\text { uterine } \\
\text { anomalies }\end{array}$} & Yes & 9 & 1 & 12 \\
\hline & No & 1 & 101 & 210 & & No & 2 & 103 & 105 \\
\hline & Total & 4 & 111 & 115 & & Total & 11 & 104 & 115 \\
\hline \multirow{3}{*}{$\begin{array}{l}\text { Bilateral } \\
\text { proximal } \\
\text { tubal } \\
\text { occlusion }\end{array}$} & Yes & 2 & 2 & 4 & \multirow{3}{*}{$\begin{array}{l}\text { Hydrosalping } \\
\text { es }\end{array}$} & Yes & 8 & 4 & 12 \\
\hline & No & 6 & 105 & 11 & & No & 3 & 100 & 103 \\
\hline & Total & 8 & 107 & 115 & & Total & 11 & 104 & 115 \\
\hline \multirow{3}{*}{$\begin{array}{l}\text { Bilateral } \\
\text { distal tubal } \\
\text { occlusion }\end{array}$} & Yes & 2 & 2 & 4 & \multirow{3}{*}{$\begin{array}{l}\text { Tubo-ovarian } \\
\text { abscess } \\
\text { (TOA) }\end{array}$} & Yes & 2 & 0 & 2 \\
\hline & No & 2 & 109 & 11 & & No & 18 & 95 & 113 \\
\hline & Total & 4 & 1011 & 115 & & Total & 20 & 95 & 115 \\
\hline \multirow{3}{*}{$\begin{array}{l}\text { Proximal } \\
\text { fallopian } \\
\text { tube } \\
\text { occlusion }\end{array}$} & Yes & 9 & 18 & 27 & \multirow{3}{*}{$\begin{array}{l}\text { Peritubal } \\
\text { adhesion }\end{array}$} & Yes & 3 & 6 & 9 \\
\hline & $\mathrm{No}$ & 8 & 80 & 88 & & No & 17 & 89 & 106 \\
\hline & Total & 17 & 98 & 115 & & Total & 20 & 95 & 115 \\
\hline \multirow{3}{*}{$\begin{array}{l}\text { Distal } \\
\text { fallopian } \\
\text { tube } \\
\text { occlusion }\end{array}$} & Yes & 4 & 13 & 17 & \multirow{3}{*}{$\begin{array}{l}\text { Normal } \\
\text { fallopian } \\
\text { tubes }\end{array}$} & Yes & 22 & 36 & 58 \\
\hline & $\mathrm{No}$ & 3 & 95 & 98 & & $\mathrm{No}$ & 31 & 36 & 57 \\
\hline & Total & 7 & 108 & 115 & & Total & 53 & 62 & 115 \\
\hline \multirow{3}{*}{$\begin{array}{l}\text { Unilateral } \\
\text { fallopian } \\
\text { tube } \\
\text { occlusion }\end{array}$} & Yes & 9 & 9 & 19 & \multirow{3}{*}{$\begin{array}{l}\text { Pathologic } \\
\text { findings }\end{array}$} & Yes & 47 & 10 & 57 \\
\hline & $\mathrm{No}$ & 3 & 94 & 97 & & No & 17 & 41 & 58 \\
\hline & Total & 12 & 103 & 105 & & Total & 64 & 51 & 115 \\
\hline
\end{tabular}


Medical Research Archives, Vol. 5, Issue 6, June 2017

Comparison of hysterosalpingography and laparoscopy in evaluation of female infertility

Table 4. Detection difference of hysterosalpingography and laparoscopic surgery

\begin{tabular}{|l|l|l|}
\hline & $\begin{array}{l}\text { Laparoscopic } \\
\text { surgery }\end{array}$ & Hysterosalpingography \\
\hline Unilateral proximal tubal occlusion & $17.4 \%$ & $7.8 \%$ \\
\hline Unilateral distal tubal occlusion & $11.3 \%$ & $3.5 \%$ \\
\hline Bilateral proximal tubal occlusion & $11.3 \%$ & $3.5 \%$ \\
\hline Bilateral distal tubal occlusion & $17.4 \%$ & $7.8 \%$ \\
\hline Proximal fallopian tube occlusion & $53.3 \%$ & $47.8 \%$ \\
\hline Distal fallopian tube occlusion & $53.3 \%$ & $47.8 \%$ \\
\hline Unilateral fallopian tube occlusion & $10.4 \%$ & $9.5 \%$ \\
\hline Bilateral fallopian tubal occlusion & $10.4 \%$ & $9.5 \%$ \\
\hline Congenital uterine anomalies & $10.4 \%$ & $9.5 \%$ \\
\hline Hydrosalpinges & $10.4 \%$ & $9.5 \%$ \\
\hline Tubo-ovarian abscess & $32.5 \%$ & $30.7 \%$ \\
\hline Peritubal adhesion & $17.4 \%$ & $7.8 \%$ \\
\hline Normal fallopian tubes & $50.4 \%$ & $49.5 \%$ \\
\hline Pathologic findings & $10.4 \%$ & $9.5 \%$ \\
\hline & &
\end{tabular}


Medical Research Archives, Vol. 5, Issue 6, June 2017

Comparison of hysterosalpingography and laparoscopy in evaluation of female infertility

Table 5. The sensitivity, specificity, accuracy, and other evaluation criteria of hysterosalpingography

\begin{tabular}{|c|c|c|c|c|c|c|c|}
\hline & $\begin{array}{c}\text { False } \\
\text { positive }\end{array}$ & $\begin{array}{c}\text { False } \\
\text { negative }\end{array}$ & $\begin{array}{c}\text { Positive } \\
\text { predictive } \\
\text { value }\end{array}$ & $\begin{array}{c}\text { Negative } \\
\text { predictive } \\
\text { value }\end{array}$ & Sensitivity & Specificity & Accuracy \\
\hline $\begin{array}{l}\text { Unilateral proximal } \\
\text { tubal occlusion }\end{array}$ & $16.2 \%$ & $30 \%$ & 0.29 & 0.96 & $70 \%$ & $83 \%$ & $83 \%$ \\
\hline $\begin{array}{l}\text { Unilateral distal } \\
\text { tubal occlusion }\end{array}$ & $0.9 \%$ & $25 \%$ & 0.23 & 0.99 & $75 \%$ & $90 \%$ & $90 \%$ \\
\hline $\begin{array}{l}\text { Bilateral proximal } \\
\text { tubal occlusion }\end{array}$ & $1.90 \%$ & $75 \%$ & 0.5 & 0.94 & $25 \%$ & $98 \%$ & $93 \%$ \\
\hline $\begin{array}{l}\text { Bilateral distal tubal } \\
\text { occlusion }\end{array}$ & $1.80 \%$ & $50 \%$ & 0.5 & 0.98 & $50 \%$ & $98 \%$ & $96 \%$ \\
\hline $\begin{array}{l}\text { Proximal fallopian } \\
\text { tube occlusion }\end{array}$ & $18.4 \%$ & $47.1 \%$ & 0.25 & 0.90 & $52.9 \%$ & $81.6 \%$ & $85.2 \%$ \\
\hline $\begin{array}{l}\text { Distal fallopian tube } \\
\text { occlusion }\end{array}$ & $12 \%$ & $42.9 \%$ & 0.23 & 0.96 & $57.9 \%$ & $52.7 \%$ & $86 \%$ \\
\hline $\begin{array}{l}\text { Unilateral fallopian } \\
\text { tube occlusion }\end{array}$ & $8.7 \%$ & $25 \%$ & 0.5 & 0.96 & $75 \%$ & $91.2 \%$ & $89.5 \%$ \\
\hline $\begin{array}{l}\text { Bilateral fallopian } \\
\text { tubal occlusion }\end{array}$ & $2.8 \%$ & $25 \%$ & 0.33 & 0.98 & $75 \%$ & $97.2 \%$ & $96.6 \%$ \\
\hline $\begin{array}{l}\text { Congenital uterine } \\
\text { anomalies }\end{array}$ & $0.09 \%$ & $18 \%$ & 0.9 & 0.98 & $8.18 \%$ & $90 \%$ & $93.3 \%$ \\
\hline Hydrosalpinges & $3.8 \%$ & $28 \%$ & 0.75 & 0.97 & $72.2 \%$ & $96.2 \%$ & $93.9 \%$ \\
\hline $\begin{array}{l}\text { Tubo-ovarian } \\
\text { abscess }\end{array}$ & 0 & $90 \%$ & 1 & 0.84 & $10 \%$ & $100 \%$ & $84 \%$ \\
\hline Peritubal adhesion & $6.3 \%$ & $85 \%$ & 0.33 & 0.83 & $15 \%$ & $93 \%$ & $80 \%$ \\
\hline $\begin{array}{l}\text { Normal fallopian } \\
\text { tubes }\end{array}$ & $58 \%$ & $58 \%$ & 0.37 & 0.45 & $42 \%$ & $58 \%$ & $41.7 \%$ \\
\hline Pathologic findings & $19.6 \%$ & $26.5 \%$ & $87 \%$ & $7 \%$ & $73.44 \%$ & $80.39 \%$ & $76.5 \%$ \\
\hline
\end{tabular}

